Research Article

\title{
Experimental and Numerical Simulation of Coal Rock Impact Energy Index Based on Peridynamics
}

\author{
Feng He $\mathbb{D}$, Tianjiao Ren, Song Yang, and Hongjie Bian \\ Department of Mechanics \& Engineering, Liaoning Technical University, Fuxin 123000, China \\ Correspondence should be addressed to Feng He; 12041827@qq.com
}

Received 29 August 2021; Revised 29 October 2021; Accepted 8 December 2021; Published 21 December 2021

Academic Editor: Xuepeng Zhang

Copyright ( $) 2021$ Feng He et al. This is an open access article distributed under the Creative Commons Attribution License, which permits unrestricted use, distribution, and reproduction in any medium, provided the original work is properly cited.

\begin{abstract}
In response to the increasing severity of the rock burst phenomenon and its relatively difficult prediction, peridynamics and indoor uniaxial compression experiments were used to calculate the changes of the internal elastic energy $(t)$ and impact energy $(c)$ for different rock masses during a loading process from an energy perspective. Two traditional indices for judging rock burst tendency-the rock elastic deformation energy index $\left(\mathrm{W}_{\mathrm{ET}}\right)$ and the rock impact energy index $\left(\mathrm{W}_{\mathrm{CF}}\right)$ - were combined to define a new actual impact energy index (W) to more accurately determine the occurrence tendency of rock bursts. The LAMMPS software was used to simulate the internal energy changes of rock materials under pressure, and the results were compared with experimental results for verification. The results were as follows: (1) in the uniaxial compression experiments of different specimens, fine sandstone had the strongest impact resistance, followed by coarse sandstone, mudstone, bottom coal seam, and top coal seam, and the obtained material properties provide a reference for predicting the rock bursts of various rock types in practical engineering. (2) The values calculated using the actual impact energy index (W) and the simulation value were 1.75 and 1.77 , respectively, which corresponded to a lower error than when the rock impact energy index $\left(\mathrm{W}_{\mathrm{CF}}\right)$ and the rock elastic deformation energy index $\left(\mathrm{W}_{\mathrm{ET}}\right)$ were used individually. Thus, this index can better predict the rock burst. (3) The simulated specimen was subjected to a gradual increase in the internal stored elastic energy during compression, which gradually decreased after the ultimate compressive strength was exceeded. The degree of impact damage formed after macroscopic crushing occurred depended on its residual energy.
\end{abstract}

\section{Introduction}

With the increasing depletion of shallow energy sources in China and energy extraction into deeper zones, the occurrence of rock bursts is becoming more and more serious [1]. Rocks bursts have a huge impact on the safety of underground staff, equipment, and materials, and this phenomenon often causes the rock to fall off or even fly out quickly, leading to the collapse of roadway supports in premining areas and even triggering disasters such as earthquakes [2-6]. To effectively prevent the occurrence of rock bursts and provide a safe environment for energy extraction, it is imperative to predict the occurrence of rock bursts so that the associated hazards can be effectively reduced.

A rock burst is a phenomenon in which the brittle rock at the free surface reaches its limit of equilibrium when the ground stress reaches a certain value, resulting in the spontaneous and rapid collapse of rock fragments to the free face, often accompanied by loud noise and air waves, which are very destructive [7]. At present, a considerable amount of research has been conducted around the world on the prediction of rock bursts, and many achievements have been obtained with various theories proposed, including strength, stiffness, energy, fractal, and concussion orientation theories [8-14]. However, owing to the complexity and uncertainty of rock bursts, the existing research results are not sufficient for making accurate and effective predictions. In particular, as the mining depth increases, the ground stress also continues to increase, and the exploding-type rock burst problem caused by it still cannot be effectively solved [15]. At the present stage, the rock impact energy index $\left(\mathrm{W}_{\mathrm{CF}}\right)$ and the rock elastic deformation energy index $\left(\mathrm{W}_{\mathrm{ET}}\right)$ are used to evaluate rock burst likelihood [16-18], but this type of index analysis causes the calculated impact energy index to be 
higher than the elastic strain energy in actual rock. Tao et al. [19] used the characteristics of a "coal surrounding rock" system, as well as the fact that the influence of the dissipative structure of the coal-rock microelement was infinitesimal in the initiation of rock bursts to argue that the occurrence of rock bursts is caused by orderly and disorderly competition within a coal rock system. Therefore, with increasing mining depth, the analysis of the damage characteristics when a rock burst occurs from an energy perspective has been a research focus.

Peridynamics simulation software provides optimized solutions for designing structures containing defective brittle materials. Therefore, in this study, uniaxial compression experiments were conducted on coarse sandstone, fine sandstone, mudstone, and the top and bottom coal seams of a mining area to analyze the differences in the impact energies and determine the impact characteristics. Experimental results were verified using peridynamics simulations to predict the energy during the occurrence of a rock burst based on the LAMMPS software and analyze the damage. The experimental results were used to construct a new rock burst occurrence index-the actual impact energy index $(\mathrm{W})$. This index was combined with the traditional rock impact energy index $\left(\mathrm{W}_{\mathrm{CF}}\right)$ and the rock elastic deformation energy index $\left(\mathrm{W}_{\mathrm{ET}}\right)$ to comprehensively judge the change of the energy within the coal rock during the process of rock burst initiation and occurrence and to provide an effective and accurate prediction approach for the exploding-type rock burst problem.

\section{Elastic Energy and Impact Energy Test Experiment}

2.1. Specimen Preparation. A variety of lithological specimens was selected from Shaanxi, China, including coarse sandstone, fine sandstone, mudstone, top coal seam, and bottom coal seam specimens. The specimens were all rectangular with the dimensions of $50 \mathrm{~mm} \times 50 \mathrm{~mm} \times 100 \mathrm{~mm}$, and the measurement error was less than $0.2 \mathrm{~mm}$. Five experiments were conducted for each specimen. Strain gauges were applied to the specimen surfaces at locations that met experimental requirements, and the actual Poisson's ratio was measured, as shown in Figure 1. Specimen numbers and parameters are shown in Table 1; for example, "CS" denotes coarse sandstone.

2.2. Experimental Method. The specimens were subjected to uniaxial compression using a universal tensile testing machine to measure the elastic energy $(t)$ and impact energy (c) of each specimen at a loading rate of $0.1 \mathrm{~mm} / \mathrm{min}$. Five experiments were conducted for each specimen, and the best results were selected as the experimental results. The details of the experiments are described as follows:

In the elastic energy $(t)$ tests, the different specimens were first subjected to a full stress-strain compression test to calculate the peak compressive stresses of the specimens. New specimens were then loaded uniaxially under compression to $80 \%-90 \%$ of the peak compressive stress,

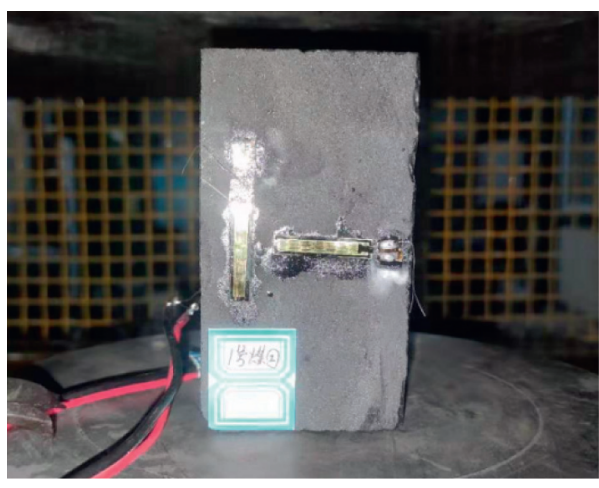

FIGURE 1: Specimen surface profile.

and then, they were unloaded. The elastic energies $(t)$ for the different types of specimens were calculated using the corresponding elastic energy calculation method. In the impact energy (c) tests, uniaxial compression tests were conducted directly on different types of specimens to obtain full stress-strain curves, and the resulting full stress-strain curves were used to calculate the impact energy (c). The flowchart of the experimental procedure is shown in Figure 2.

\section{Experimental Results}

3.1. Elastic Energy (t) Test Results and Calculations. The stress-strain curves for the change in the elastic energy $(t)$ of the optimal specimens in the experiments are shown in Figure 3. The unloading peak stresses and strains for different specimens are shown in Table 2.

The traditional indicator used to judge the occurrence tendency of a rock burst based on the elastic energy $(t)$ is the ratio of the elastic strain energy to the plastic strain energy proposed by Kidybinski [20], i.e., the ratio of the area enclosed during unloading to the area enclosed during loading. These energies are illustrated in Figure 4, where $E_{\mathrm{e}}$ is the elastic strain energy, $E_{\mathrm{p}}$ is the loss strain energy, $f(\varepsilon)$ is the loading curve, and $f_{1}(\varepsilon)$ is the unloading curve.

The ratio of elastic strain energy to plastic strain energy is defined as $\mathrm{W}_{\mathrm{ET}}$.

$$
W_{\mathrm{ET}}=\frac{E_{e}}{E_{p}} .
$$

The $\mathrm{W}_{\mathrm{ET}}$ values of the different specimens in the experiment were calculated using equation (1), and the results are shown in Table 3.

According to China's coal industry standard MT/T1742000 "Classification of coal seam impact tendency and determination method of index," the criterion for classifying the coal rock is as follows:

$$
\begin{cases}W_{\mathrm{ET}} \geq 5, & \text { strong, } \\ 2 \leq W_{\mathrm{ET}} \leq 5, & \text { weak, } \\ W_{\mathrm{ET}} \leq 2, & \text { nil. }\end{cases}
$$

This criterion applies to coal seams with low metamorphism and water-rich seams, particularly those with 
TABLE 1: Physical parameters of different types of specimens.

\begin{tabular}{lccccc}
\hline Specimen type and number & $\begin{array}{c}\text { Coarse sandstone, } \\
\text { CS }\end{array}$ & Fine sandstone, XS & Mudstone, NY & Top coal seam, 1M & $\begin{array}{c}\text { Bottom coal seam, } \\
4 \mathrm{M}\end{array}$ \\
\hline Density & 273.9 & 277.8 & 281.4 & 175.7 & 22.46 \\
Modulus of elasticity $\left(\times 10^{5}\right)$ & 5.2 & 5.2 & 3.5 & 1.2 & 1.2 \\
$(\mathrm{MPa})$ & 0.249 & 0.25 & 0.33 & 0.3 & 0.3 \\
Poisson's ratio & & & \\
\hline
\end{tabular}

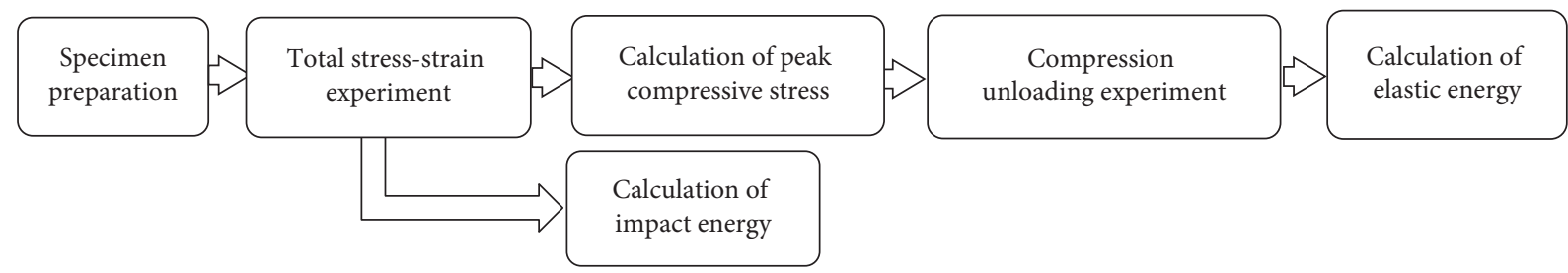

Figure 2: Experimental flowchart.

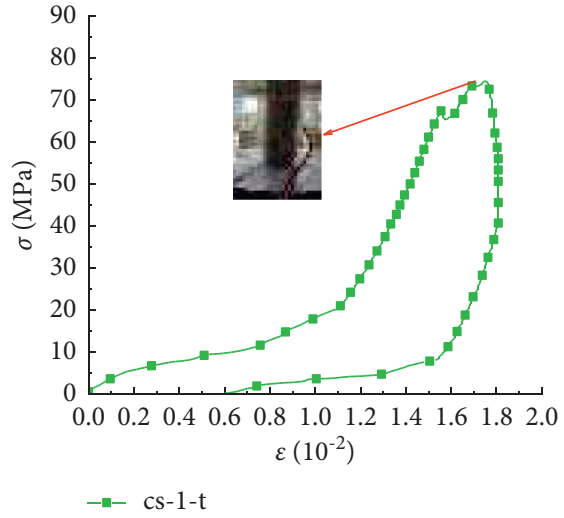

(a)

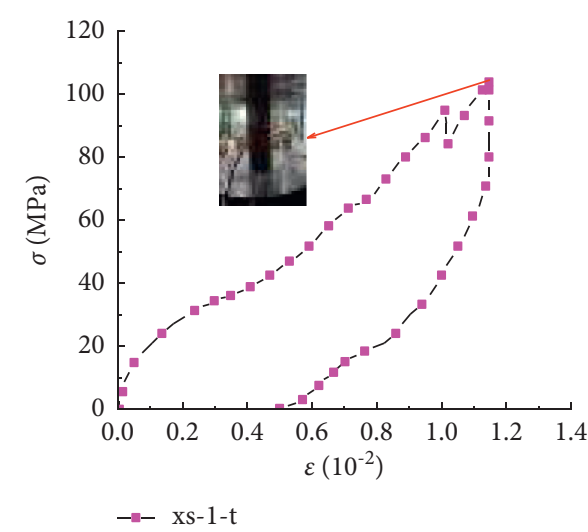

(b)

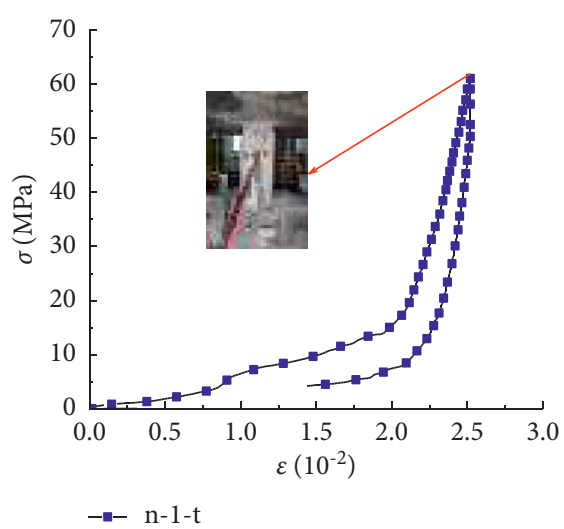

(c)

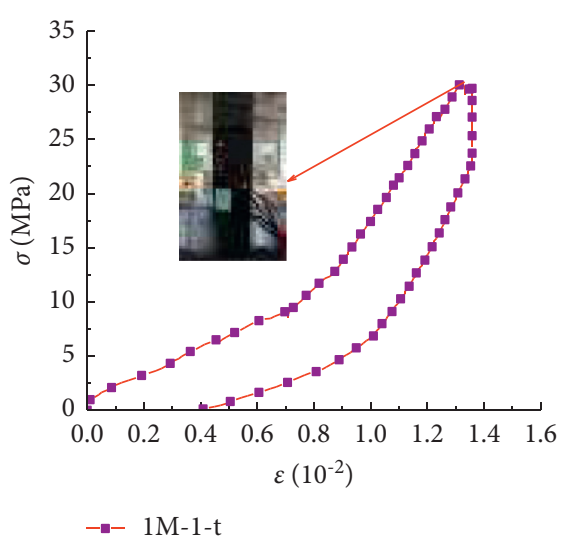

(d)

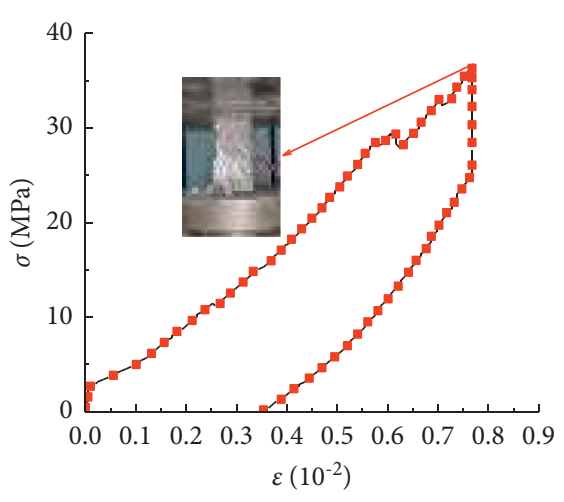

$-4 \mathrm{M}-1-\mathrm{t}$

FIgURE 3: Stress-strain curves of different specimens from elastic energy ( $t$ ) tests. (a) CS-t, (b) XS-t, (c) NY-t, (d) 1M-t, and (e) 4M-t.

TABLE 2: Unloading peak stresses and strains for different types of specimens.

Specimen type and number Coarse sandstone, CS Fine sandstone, XS Mudstone, NY Top coal seam, 1M Bottom coal seam, 4M

\begin{tabular}{llllll}
\hline Unloading peak stress $(\mathrm{MPa})$ & 75.41 & 108.25 & 63.72 & 31.87 & 37.25
\end{tabular}

Unloading peak strain $\left(10^{-2}\right)$

1.72

1.17

2.51

1.37

0.74 


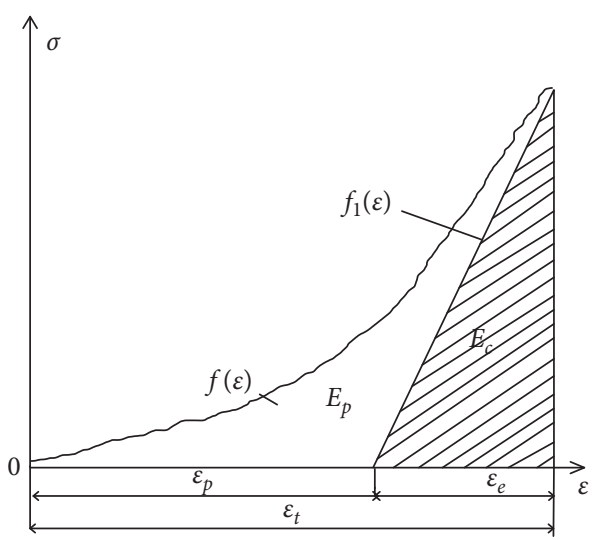

FIgURE 4: Model diagram for calculating $\mathrm{W}_{\mathrm{ET}}$ elastic energy $(t)$.

TABLE 3: $\mathrm{W}_{\mathrm{ET}}$ values for different types of specimens.

\begin{tabular}{lccccc}
\hline Specimen type & CS & XS & NY & $1 \mathrm{M}$ & $4 \mathrm{M}$ \\
\hline $\mathrm{W}_{\mathrm{ET}}$ & 6.05 & 1.99 & 23.41 & 35.54 & 27.50 \\
\hline
\end{tabular}

long-flame coals, and it can be used for depths as low as $800 \mathrm{~m}$ below the ground.

The criterion for a hard rock is as follows:

$$
\begin{cases}W_{\mathrm{ET}} \geq 15, & \text { strong, } \\ 10 \leq W_{\mathrm{ET}} \leq 15, & \text { weak, } \\ W_{\mathrm{ET}} \leq 10, & \text { nil. }\end{cases}
$$

The criterion applies to a hard rock with low metamorphism, such as sandstone and marble.

According to Table 3, equations (2), and (3), the rock burst occurrence tendencies of the experimental specimens from strong to weak were $1 \mathrm{M}, 4 \mathrm{M}, \mathrm{NY}, \mathrm{CS}$, and XS, as shown in Figure 5.

\subsection{Impact Energy (c) Test Results and Calculations.} When a specimen is unloaded such that its $\mathrm{W}_{\mathrm{ET}}$ value is $80 \%$ to $90 \%$ of the corresponding loaded value, the longitudinal wave velocity decay rate of the specimen will be significant [21]. The reason is that the specimen's internal primary fracture expansion and secondary fracture generation are the most violent, and therefore, the calculated $\mathrm{W}_{\mathrm{ET}}$ does not really represent the ratio of the true elastic strain energy to the plastic strain energy inside the specimen under the influence of the wave velocity.

Many problems predicted based on the traditional rock elastic deformation energy index $\mathrm{W}_{\mathrm{ET}}$ and the uniaxial compression process of the specimen can be seen as a phenomenon occurring under compressive conditions of the rock burst. Therefore, various scholars have used the full stress-strain curve after uniaxial compression to simulate the process of rock burst occurrence. The ratio of the area enclosed before the peak of the stress-strain curve $\left(E_{1}\right)$ to the area enclosed after the peak $\left(E_{2}\right)$ was used to determine the criterion for the occurrence of rock bursts. These energies are illustrated in Figure 6.

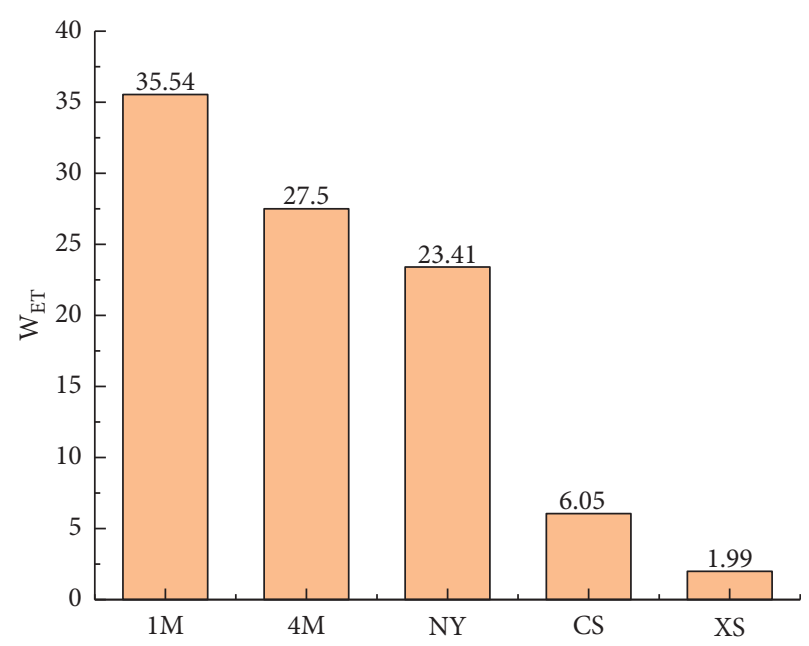

FIgURE 5: Rock burst occurrence tendencies based on calculated $\mathrm{W}_{\mathrm{ET}}$ values.

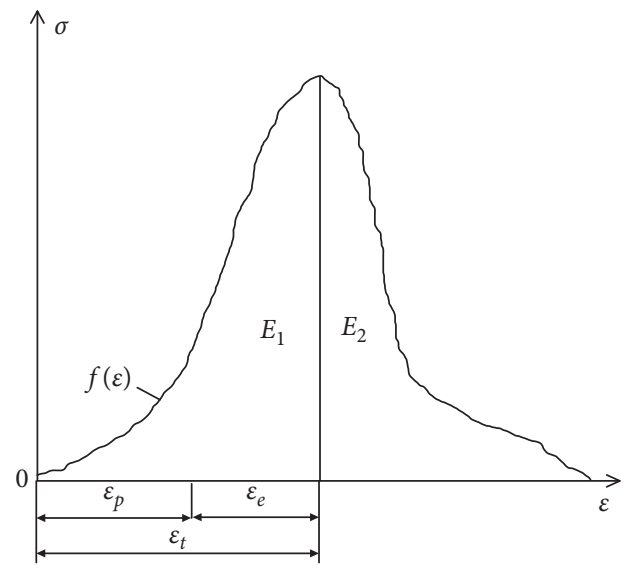

Figure 6: Model diagram for calculating $\mathrm{W}_{\mathrm{ET}}$.

The ratio of the area enclosed before the peak $\left(E_{1}\right)$ to the area enclosed after the peak $\left(E_{2}\right)$ is defined as $\mathrm{W}_{\mathrm{CF}}$.

$$
W_{\mathrm{CF}}=\frac{E_{1}}{E_{2}} \text {. }
$$

The full stress-strain curves from the impact energy (c) tests of the optimum specimens are shown in Figure 7. The peak compressive stresses and strains of different specimens are shown in Table 4 . The $\mathrm{W}_{\mathrm{CF}}$ values of different specimens in the experiment were calculated using equation (4) and the data in Table 4. The results are shown in Table 5.

According to China's coal industry standard MT/T1742000 Classification of coal seam impact tendency and index measurement method, the criterion for judging the occurrence of rock bursts using $\mathrm{W}_{\mathrm{CF}}$ is as follows:

$$
\begin{cases}W_{\mathrm{CF}} \geq 3, & \text { strong, } \\ 2 \leq W_{\mathrm{CF}} \leq 3, & \text { weak, } \\ W_{\mathrm{CF}} \leq 2, & \text { nil. }\end{cases}
$$

The rock burst occurrence tendencies of the specimens from strong to weak were $1 \mathrm{M}, 4 \mathrm{M}, \mathrm{NY}, \mathrm{CS}$, and XS, as shown in Figure 8. 


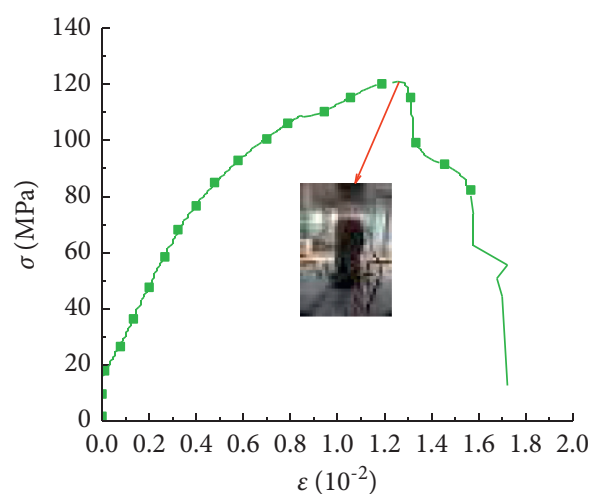

$-\varpi-c s-1-c$

(a)

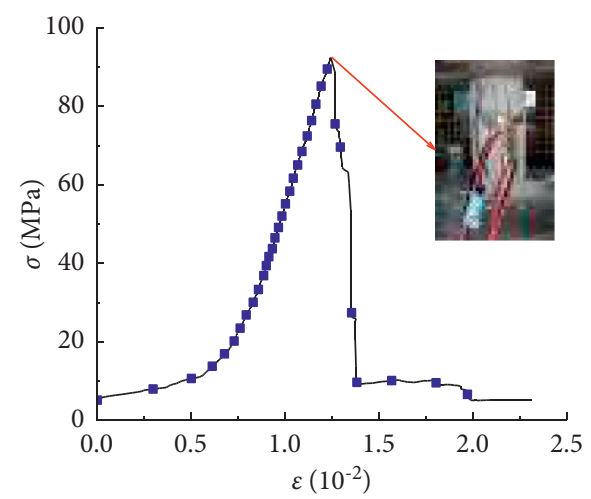

$-n-n-1-c$

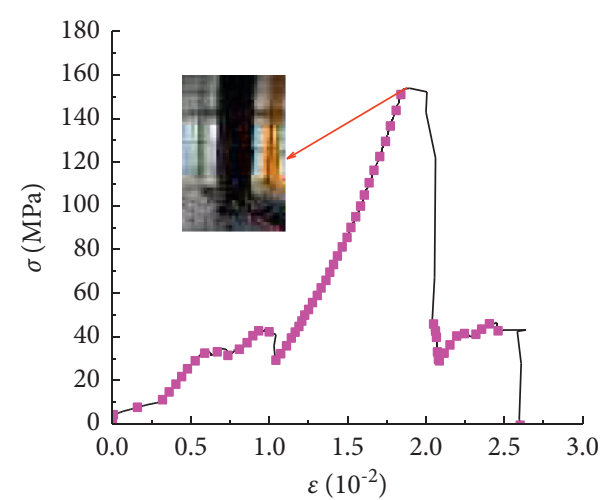

$- \pm \mathrm{xs}-1-\mathrm{c}$

(b)

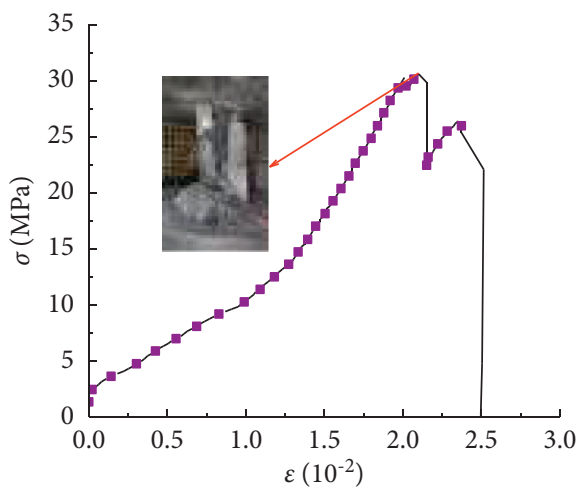

$-1 \mathrm{M}-1-\mathrm{c}$

(d)

(c)

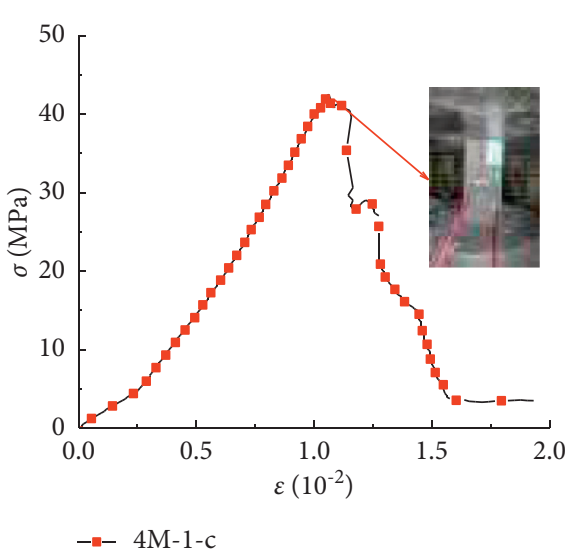

(e)

FIGURE 7: Full stress-strain curves for different specimens from impact energy. (a) CS-c, (b) XS-c, (c) NY-c, (d) 1M-c, and (e) 4M-c.

TABLE 4: Compressive peak stresses and strains for different types of specimens.

\begin{tabular}{lccccc}
\hline Specimen type and number & Coarse sandstone, CS & Fine sandstone, XS & Mudstone, NY & Top coal seam, 1M & Bottom coal seam, $4 \mathrm{M}$ \\
\hline Peak compressive stress (MPa) & 121.15 & 147.52 & 92.15 & 32.26 & 42.56 \\
Peak compressive strain $\left(10^{-2}\right)$ & 1.72 & 2.59 & 2.29 & 2.50 & 1.91 \\
\hline
\end{tabular}

TABLE 5: $\mathrm{W}_{\mathrm{CF}}$ values for different types of specimens.

\begin{tabular}{lccccc}
\hline Specimen type & CS & XS & NY & $1 \mathrm{M}$ & $4 \mathrm{M}$ \\
\hline $\mathrm{W}_{\mathrm{CF}}$ & 4.53 & 2.17 & 16.25 & 18.10 & 37.52 \\
\hline
\end{tabular}




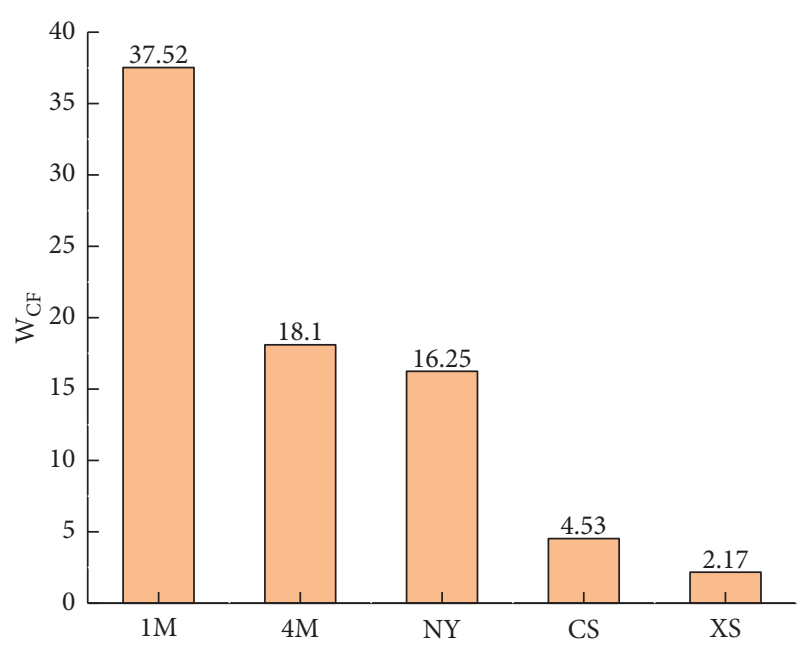

FIGURE 8: Rock burst occurrence tendencies based on calculated $\mathrm{W}_{\mathrm{CF}}$ values.

3.3. Actual Impact Energy Index (W). When calculating $\mathrm{W}_{\mathrm{CF}}$, owing to the crude determination of the rock's internal energy at the time of the rock burst $\left(E_{1}\right)$, the actual elastic energy stored in the rock is exaggerated, which leads to a larger calculated value than the actual value. When calculating $\mathrm{W}_{\mathrm{ET}}$, however, the specimen's internal energy before the peak is divided into the $E_{\mathrm{e}}$ elastic strain energy and the $E_{\mathrm{p}}$ loss strain energy. The advantage of this is that the actual elastic energy stored inside the rock is subdivided and reduced. Thus, combining the two indices and defining a new actual impact energy index (W) will reduce the errors associated with the individual predictions of $\mathrm{W}_{\mathrm{ET}}$ and $\mathrm{W}_{\mathrm{CF}}$. The actual impact energy index $(\mathrm{W})$ is the ratio of the elastic strain energy $E_{\mathrm{e}}$ stored before the peak of the stress-strain curve to the strain energy $E_{2}$ released after the peak as follows:

$$
\begin{aligned}
W & =\frac{E_{e}}{E_{2}} \\
& =\frac{W_{\mathrm{CF}} \cdot W_{\mathrm{ET}}}{1+W_{\mathrm{ET}}} .
\end{aligned}
$$

These energies are illustrated in Figure 9. Based on equation (5), Figure 9, and the results in Tables 3 and 5, the actual impact energy index (W) values of the different specimens in the experiment were calculated, and the results are shown in Table 6.

Based on equations (2), (3), and (5) and the formula for the actual impact energy index $\mathrm{W}$, the criteria for the occurrence of rock bursts with the actual impact energy index $\mathrm{W}$ are as follows:

Criterion for the coal rock:

$$
\begin{cases}W \geq 2.5, & \text { strong } \\ 1.33 \leq W \leq 2.5, & \text { weak } \\ W \leq 1.33, & \text { nil. }\end{cases}
$$

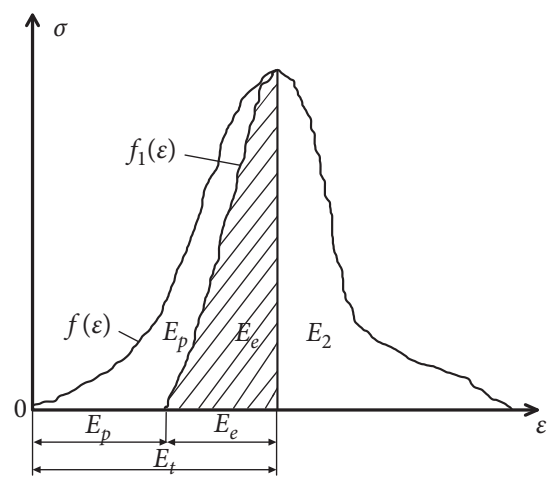

FIgURE 9: Model diagram for calculating W.

TABLe 6: $\mathrm{W}$ values for different types of specimens.

\begin{tabular}{lccccc}
\hline Specimen type & CS & XS & NY & $1 \mathrm{M}$ & $4 \mathrm{M}$ \\
\hline $\mathrm{W}$ & 2.66 & 1.81 & 11.67 & 12.62 & 27.51 \\
\hline
\end{tabular}

Criterion for the hard rock:

$$
\begin{cases}W \geq 2.81, & \text { strong, } \\ 1.82 \leq W \leq 2.81, & \text { weak, } \\ W \leq 1.82, & \text { nil. }\end{cases}
$$

The rock burst occurrence tendencies based on $\mathrm{W}$ for the different specimens from strong to weak were $1 \mathrm{M}, 4 \mathrm{M}, \mathrm{NY}$, $\mathrm{CS}$, and XS, as shown in Figure 10.

Both the elastic deformation energy index $\left(\mathrm{W}_{\mathrm{ET}}\right)$ and the rock impact energy index (WCF) were greater than the actual impact energy index (W) in the five sets of experiments, and the resulting rock burst occurrence tendencies of the specimens are shown in Table 7.

As shown in Tables 3 and 5, the $\mathrm{W}_{\mathrm{ET}}$ and $\mathrm{W}_{\mathrm{CF}}$ values for the XS specimen were 1.99 and 2.17, respectively. This specimen was judged based on equations, and (2), (3), and (5) to have a weak tendency for rock burst occurrence. However, its $\mathrm{W}$ value was 1.81, and thus, no rock burst should occur according to equations (7) and (8). The three results are conflicting. According to the calculation of $\mathrm{W}$, even if the rock burst occurs, the elastic energy generated by the rock burst is almost entirely used for its own fragmentation so that the rock burst should be extremely weak or not occur at this time. Thus, the actual impact energy index (W) constructed is valid.

\section{Numerical Simulation}

4.1. Building an Energy Prediction Mechanics Model. A program was written to simulate rock material loading from the perspective of peridynamics using the Python language. The LAMMPS atomic molecular parallel simulator was used to simulate and build discrete models of peridynamics (PD) without grids. After loading the model, the output file format was changed via a converter and imported into postprocessing software to observe the specific deformation 


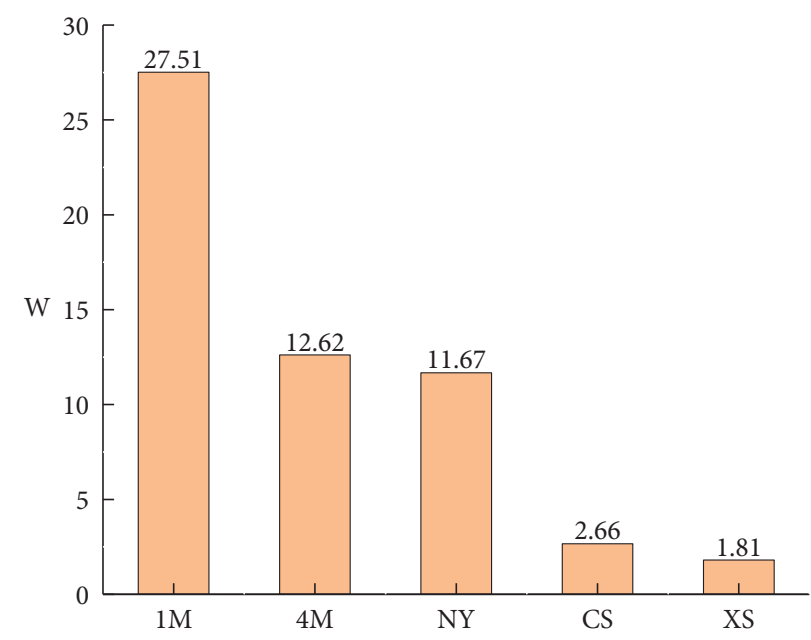

FIGURE 10: Rock burst occurrence tendencies based on from W.

TABLE 7: Rock burst occurrence tendencies for different types of specimens.

\begin{tabular}{lccc}
\hline Specimen lithology & $\mathrm{W}_{\mathrm{ET}}$ & $\mathrm{W}_{\mathrm{CF}}$ & $\mathrm{W}$ \\
\hline $1 \mathrm{M}$ & Strong & Strong & Strong \\
$4 \mathrm{M}$ & Strong & Strong & Strong \\
$\mathrm{NY}$ & Strong & Strong & Strong \\
$\mathrm{CS}$ & Strong & Strong & Weak \\
XS & Strong & Weak & No \\
\hline
\end{tabular}

damage and energy distribution of the model. The model was set as a rectangular specimen with the dimensions of $50 \mathrm{~mm} \times 50 \mathrm{~mm} \times 100 \mathrm{~mm}$. The density was $1.87 \mathrm{~g} / \mathrm{cm}^{2}$, Poisson's ratio was 0.3 , the modulus of elasticity $E$ was $1.2 \times 105 \mathrm{MPa}$, the critical elongation s0 was set to 0.02 , time step was set to $1.0 \mathrm{~s}$, and the total number of time steps was set to 20,000. The simulated specimen was discretized into 500,000 material points with material point spacings of $\Delta=0.1 \mathrm{~mm}$ and $\delta=3.015 \Delta$ [22-27]. The lower boundary was fixed, and a uniform load was applied to the upper boundary at a rate of $0.1 \mathrm{~mm} / \mathrm{min}$. To improve the simulation result accuracy, the relaxation time was increased to unload the initial stress and return the simulated specimen from an excited state to an equilibrium arrangement. This reinforced the relaxation process and allowed the crack expansion and internal energy transformation to be observed.

In addition, since peridynamics is a nonlocal theory, the PD model was used in the simulations to model the mechanical properties of the rock material. The constitutive equation is as follows:

$$
\rho(x) \ddot{u}(x, t)=\int_{H} f(\eta, \varepsilon) \mathrm{d} V_{x}+b(x, t), \quad \forall x \in R,
$$

where $\rho$ is the material density, $\mu$ is the displacement field vector, $B$ is the external density, and $\mathrm{H}$ is the field of action at the specified point.
Based on the PD theory of bonds, the force function $f$ can be expressed as follows:

$$
f(n, \eta)= \begin{cases}c s(1-D) \frac{\eta+\xi}{|\eta+\xi|}, & s_{c}<s<s_{e c} \cup s_{e t}<s<s_{t}, \\ c s \frac{\eta+\xi}{|\eta+\xi|}, & s_{e t}<s<s_{e t}, \\ 0, & \text { others. }\end{cases}
$$

The stress damage clouds are shown in Figures 11-14. The damage stages are described as follows:

Stage 1. Closed phase under pressure: At the beginning of the simulation, the model was in the pressure consolidation stage. The stresses were not concentrated at the edges, and the values were small. The stresses were mainly concentrated in the middle of the model, and the values were large. The stress concentration was evident in the middle of the coal rock model. This proved that this stage was the initial stage of pressure on the coal rock, resulting in the gradual closure of its internal microcracks and micropores. At this point, slight deformation occurred in the central position of the model, which was not evident at the macroscale. 


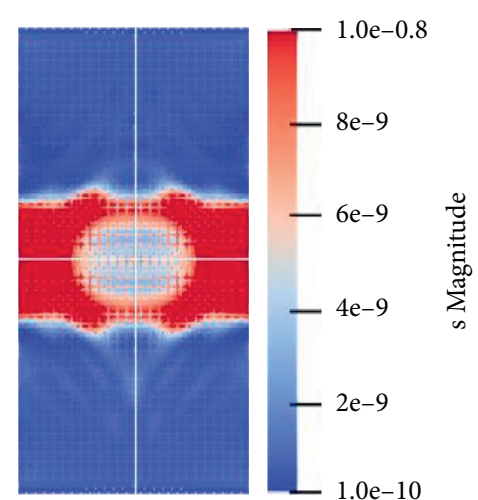

FIGURE 11: Stress damage cloud in closed phase under pressure.

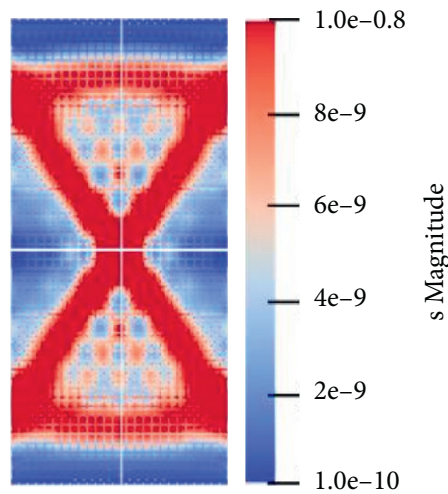

Figure 12: Stress damage clouds in elastic linear deformation phase.

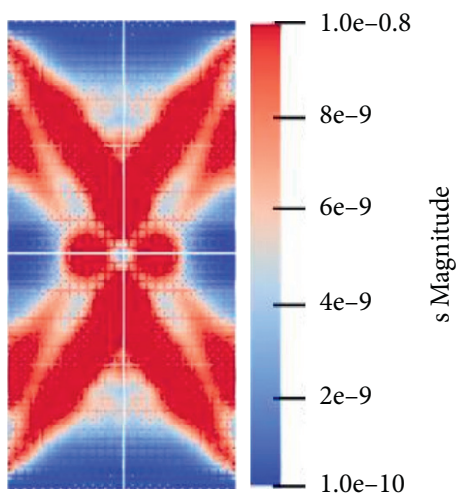

FIGURE 13: Stress damage cloud in nonlinear deformation phase.

Stage 2. Linear elastic deformation stage: As the pressure increased, the stress within the model gradually spread, forming a " $\nabla$ " distribution in a shape similar to an " $X$." At this point, the bonds within the model had only deformed and not broken, meaning that the specimen was in the linear elastic phase and the deformation was reversible, i.e., if the external force was removed, the specimen deformation would reverse.

Stage 3. Nonlinear deformation stage: At this stage, the model stress distribution gradually stabilized with an " $X$ " distribution. As the pressure gradually increased,

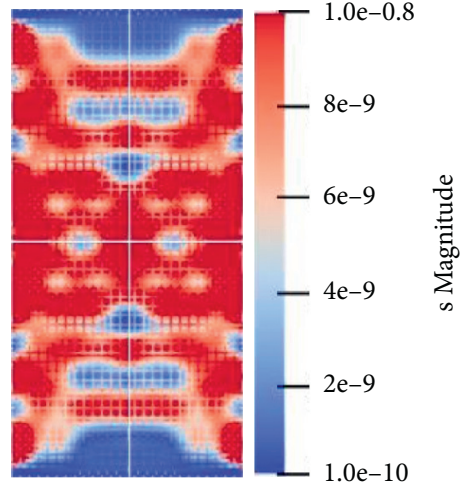

Figure 14: Stress damage clouds in macroscopic damage phase.

many bonds within the model cracked along the stress distribution area, and damage occurred to the specimen. At this point, the specimen showed macroscopic cracking, elongation, convergence, crossover, and penetration with an " $X$ "-shaped main crack and many tiny cracks in the vicinity of the main crack. The macroscopic analysis of the coal specimen revealed that many cracks expanded rapidly, resulting in " $X$-"shaped cracks and leading to cracking of the coal rock. The crack direction and shape were basically stable.

Stage 4. Macroscopic damage stage: As the pressure increased, the stress spread throughout the model, and the stress on the model reached its ultimate state. Macroscopically, the damage evolution increased and reached the yield stress, and cracks continued to develop, cross, converge with each other, and penetrate the specimen, leading to specimen damage.

The stress-strain curve obtained from the simulation is shown in Figure 15. During the deformation of the simulated specimen, all the work performed by the compressive stress was transformed into the internal elastic strain energy and the plastic strain energy. The elastic strain energy that accumulated inside the specimen differed from the plastic strain energy losses at different stages of damage. First, during the phase in which microcracks are closed by external pressure, the compressive stress mainly compacted the specimen to strengthen it, and the energy was consumed in the process of the microcracks being compacted. With the compacting of microcracks, the specimen entered a linear elastic deformation phase, where most of the work performed by the compressive stress was transformed into the internal energy of the specimen, and the more time this phase lasted, the greater the elastic strain energy inside the specimen became. The specimen then entered a nonlinear deformation phase, where most of the work performed by the compressive stress was transformed into the creation of new cracks and joint structures. As the number of secondary cracks increased and penetrated the specimen, damage occurred to the specimen at the macroscopic level. When the applied compressive stress exceeded the ultimate strength of the specimen, the coal began to break down, and its internal energy began to diminish, at which point a large amount of 
elastic strain energy inside the specimen began to be released. When the energy released was greater than the energy required for crack expansion, the damage intensified until sudden macroscopic crushing occurred, at which point the remaining energy was released in the form of kinetic energy, and the size of the resulting impact damage was dependent on the amount of energy remaining.

The change in the internal energy of the specimen, namely, the change in the magnitudes of the elastic energy and the impact energy, was the main factor determining whether a rock burst occurred. To verify the accuracy of the simulation results and the release of the energy when the rock was damaged by impact, the fine sandstone curve from the experiment was chosen for comparison with the simulated curve, as shown in Figure 16. The experimental and simulated curves followed roughly the same trend, and there was rebound in both the closed phase under pressure and the linear elastic phase, indicating that the elastic strain energy was generated and increased during the compression process. A sudden drop in the stress occurred upon entering the nonlinear elastic phase, where the internal energy began to be released, resulting in an "X"-shaped macroscopic damage to the specimen.

The impact tendencies of the simulated specimens were calculated using three indices and compared with the calculated values based on the experiments, as shown in Table 8 . The calculated $\mathrm{W}_{\mathrm{ET}}$ and $\mathrm{W}_{\mathrm{CF}}$ values had large errors compared with the simulated results, while the constructed actual impact energy index (W) had the smallest error and was basically consistent with the actual results, which further verified the accuracy of simulation. The results showed that the actual impact energy index (W) is the optimal index to judge the rock burst tendency.

\section{Additional Points and Discussion}

In this study, the impact tendencies of rock materials were determined using peridynamics simulations and indoor uniaxial compression experiments. Combined with the standard indices $\mathrm{W}_{\mathrm{ET}}$ and $\mathrm{W}_{\mathrm{CF}}$ in the Chinese coal industry standard MT/T174-2000 Classification of coal seam impact tendency and index determination method, the actual impact energy index $\mathrm{W}$ was derived, with the following conclusions:

(1) The analysis of the elastic deformation energy index $\left(\mathrm{W}_{\mathrm{ET}}\right)$ and the rock impact energy index $\left(\mathrm{W}_{\mathrm{CF}}\right)$ showed that there were large errors in their respective prediction abilities of the impact tendency. For the actual impact energy index (W) obtained by combining the two, the theoretically calculated value was 1.75 and the simulated value was 1.77 . The error was smaller than when using the standard indices individually, and $\mathrm{W}$ could be used to predict the occurrence tendency of rock bursts more accurately.

(2) Impact experiments were conducted on a variety of materials, and the results showed that the fine sandstone had the strongest impact resistance, followed by coarse sandstone, mudstone, bottom coal seam, and top coal seam. This provides a reference

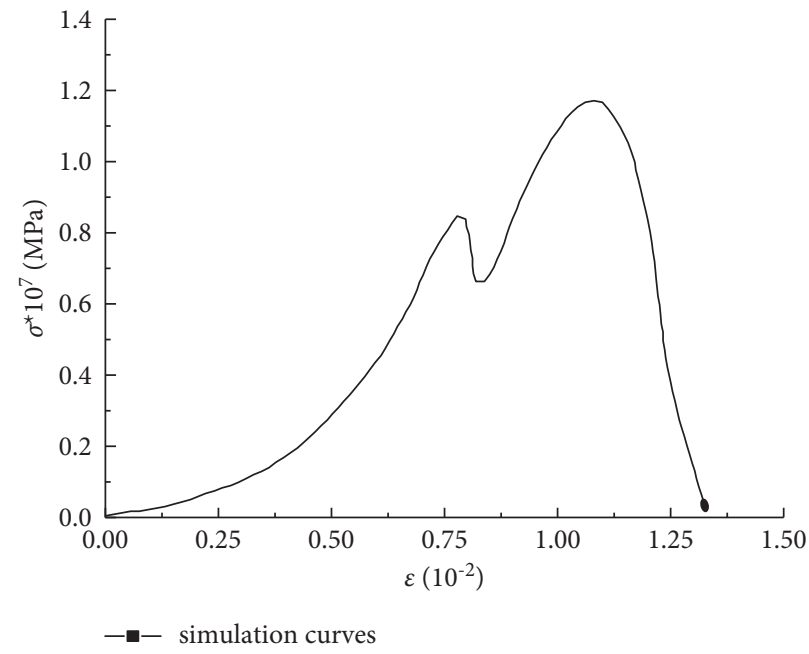

FIGURE 15: Simulated stress-strain curves.

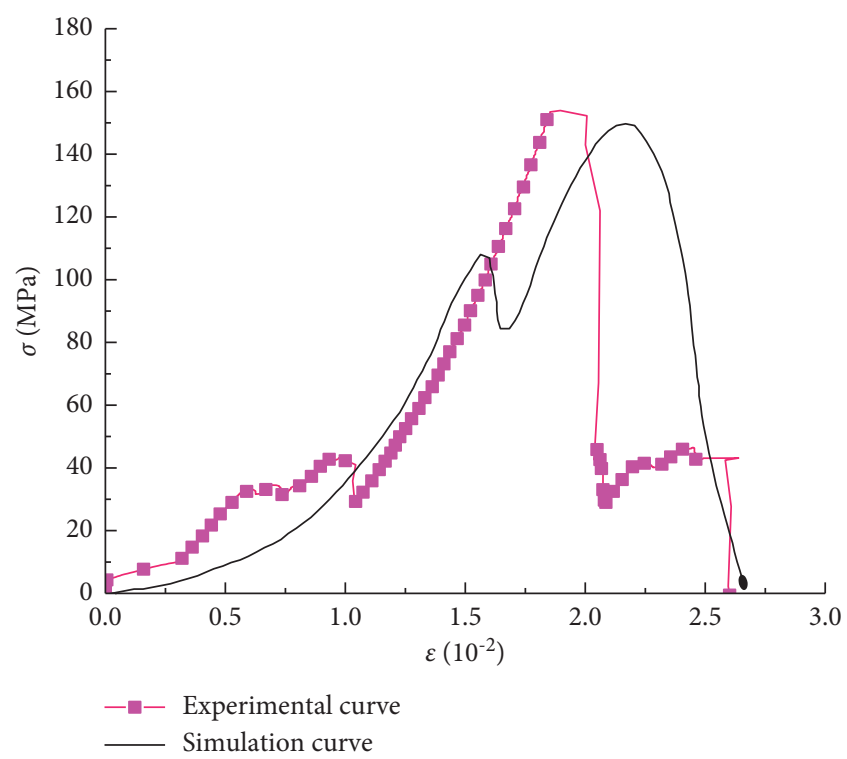

Figure 16: Comparison of experimental curves and simulation results for fine sandstone.

TABle 8: Comparison of calculated values based on experiments and simulated values for three indices.

\begin{tabular}{lccc}
\hline & $\mathrm{W}_{\mathrm{ET}}$ & $\mathrm{W}_{\mathrm{CF}}$ & $\mathrm{W}$ \\
\hline Calculated values & 4.9 & 5.1 & 1.75 \\
Simulated values & 6.4 & 3.9 & 1.77 \\
Differences & Lower & Higher & Approximate equality \\
\hline
\end{tabular}

for predicting rock bursts of various types of rock in practical engineering.

(3) Peridynamics simulations were conducted using the LAMMPS software to examine the change of the internal energy when a rock burst occurred. The internal stored elastic energy gradually became larger during the simulated compression of the specimen, and then, it gradually decreased after the ultimate 
compressive strength was exceeded. The degree of the impact damage after macroscopic crushing occurred depended on the amount of residual energy.

\section{Data Availability}

The data used to support the findings of this study are included within the article.

\section{Conflicts of Interest}

The authors declare that they have no conflicts of interest.

\section{Acknowledgments}

This research was supported by General Programs of the National Natural Science Foundation of China (Grant no. 51774167).

\section{References}

[1] F. Gong, X. Li, and W. Zhang, "Prediction of rock burst occurrence and intensity classification in underground engineering based on Bayes discriminant analysis method," Geotechnical Mechanics, vol. 31, no. S1, pp. 370-437+387, 2010.

[2] P. Jia, Q. Shamg, M. Zhi, and L. Du, "Rockburst prediction based on evidence theory," Chinese Journal of Geotechnical Engineering, vol. 36, no. 6, pp. 1079-1086, 2014.

[3] P. Yan, Z. Zhao, W. Lu, Y. Fan, Chen, and Shan, "Mitigation of rock burst events by blasting techniques during deeptunnel excavation," Engi-neeringGeology, vol. 188, no. (1), pp. 126-136, 2015.

[4] B. Wang, X. Li, and C. Ma, "Dynamic and static combined support principle and preliminary application for rock burst disaster control," Journal of Rock Mechanics and Engineering, vol. 33, no. 6, pp. 1169-1178, 2014.

[5] R. Ruifeng, Y. Yanwu, J. Jianhui, Z. Haodong, G. Yuan, and C. Hao, "Effect of rock burst risk on lateral pressure coefficient in rectangular roadway," Study Journal of Central North University (Natural Science Edition), vol. 42, no. 2, pp. 117122, 2021.

[6] Z. Tang, X. Wang, and Q. Xu, "Rock burst prediction based on oversampling and objective weighting method," Journal of Tsinghua University, vol. 61, no. 6, pp. 543-555, 2021.

[7] K. Wang, "An overview of rock burst prediction and prevention techniques in deep buried tunnels," Tunnel Construction, vol. 41, no. 2, pp. 212-224, 2021, (in English and Chinese).

[8] S. Liu, J. Liang, and G. Fang, "The Peridynamics and finite element method are coupled to solve the damage problem of composite materials," Chinese Science: Technical Science, vol. 49, no. 10, pp. 1215-1222, 2019.

[9] C. Zhiyong, S. Guoshao, H. Xiaohua, Z. Jianwen, and Z. Lianjun, "Development of Peridynamics and simulation of rock fracture process," Journal of solid Mechanics, vol. 40, no. 4, pp. 354-371, 2019.

[10] J. Wang, S. Qian, and H. Shi, "Numerical simulation of wave scattering and cracking expansion of brittle materials by peridynamics theory," Science Technology and Engineering, vol. 19, no. 11, pp. 1-9, 2019.

[11] S. Hengshun, Q. Songrong, Z. Guohao, X. Ting, and Y. Qunsheng, "Fatigue fracture analysis," based on
Peridynamics theory Mechanical strength, vol. 40, no. 4, pp. 954-960, 2018.

[12] Q. Pizhong, Z. Yong, Z. Heng, and H. Yang, "Advances in peridynamics," Research Quarterly Journal of Mechanics, vol. 38, no. 1, pp. 1-13, 2017.

[13] Q. Zhang, Y. Y. Tian, and X. Gu, "Hybrid modeling method for peridynamics and finite element method," Journal of Computational Mechanics, vol. 33, no. 4, pp. 441-448, 2016.

[14] X. Liu, W. Yang, and X. Zhang, "A multidimensional cloud model rockburst prediction based on improved hierarchy method and CRITIC method," Journal of Hunan University, vol. 48, no. 2, pp. 118-124, 2021.

[15] L. Gao, Z. Liu, and H. Zhang, "Prediction of rock burst classification in railway tunnel based on hybrid PSO-RBF neural network," Journal of Railway Science and Engineering, vol. 18, no. 2, pp. 450-458, 2021.

[16] R. R. Up, X. Yan, and F. Cao, "Study on the technology of impact pressure prevention and control angle coal mining with complex conditions," Coal Mine Modernization, vol. 30, no. 2, pp. 72-76, 2021.

[17] D. Xiaomin, N. Jiasheng, X. Zaijun et al., "Occurrence mechanism of impact ground pressure in stratified mining stratified mining in slanting thick coal seam," Coal mine safety, vol. 51, no. 11, pp. 89-93, 2020.

[18] W. Jiliang, C. Jianping, Y. Jing, and Q. Jinsheng, "Method and application of distance discriminating analysis for grade determination of rockburst," Geotechnical Mechanics, vol. 30, no. 7, pp. 2203-2208, 2009.

[19] F. Tao, P. Changliang, W. Hongtu, C. Ping, and W. Wenxing, "A new method for measuring energy index of elastic deformation of rockburst rock," Chinese Journal of Nonferrous Metals, no. 2, pp. 165-168, 1998.

[20] A. Kidybinski, "Bursting liability indices of coal," International Journal of Rock Mechanics and Mining Sciencesఓ $\triangleleft e o m e c h a n i c s$ Abstracts, vol. 18, no. 4, pp. 295-304, 1981.

[21] H. Li, J. Liu, and L. Wang, "Effect of liquid nitrogen cold loading on structural damage of coal samples with different joints," Journal of coal, vol. 5, no. 12, pp. 2019-1223, 2020.

[22] L. Baofu, Q. Liwei, R. Yongkang, and C. Bei, "Relationship between uniaxial compressive strength and impact energy index of Qianqiu coal mine," Coal Engineering, no. 12, pp. 68-70, 2011.

[23] Z. Du, "Test and analysis on impact tendency of coal and rock in a coal mine," Modern Mining, vol. 36, no. 4, pp. 212-215, 2020.

[24] F. Xiating, C. Bingrui, M. Huajun et al., "The law and mechanism of rock burst in deep buried tunnel: instant rock burst," Journal of Rock Mechanics and Engineering, vol. 31, no. 3, pp. 433-444, 2012.

[25] F. Shen, Q. Zhang, D. Huang, and J. Zhao, "Simulation of axial tensile failure of concrete based on Peridynamics theory," Journal of Computational Mechanics, vol. 30, no. S1, pp. 79-83, 2013.

[26] F. Shen, Q. Zhang, D. Huang, and J. Zhao, "Peridynamics simulation of concrete structure failure under impact load," Engineering Mechanics, vol. 29, no. S1, pp. 12-15, 2012.

[27] H. Zhu, F. Xu, and H. Yang, "Two-dimensional fatigue crack propagation model based on Peridynamics," Journal of Southeast University (Natural Science Edition), vol. 50, no. 4, pp. 705-711, 2020. 